\title{
Chitosan-Polyoxometalate Nanocomposites: Synthesis, Characterization and Application as Antimicrobial Agents
}

\author{
G. Fiorani - O. Saoncella $\cdot$ P. Kaner $\cdot$ S. A. Altinkaya $\cdot$ \\ A. Figoli $\cdot$ M. Bonchio $\cdot$ M. Carraro
}

Received: 1 October 2013/Published online: 9 January 2014

(C) Springer Science+Business Media New York 2014

\begin{abstract}
Polyoxometalates (POMs) were used, together with chitosan (CS), to obtain hybrid nanoaggregates. Three representative POMs were efficiently assembled into nanoparticles of few hundred nm diameter, featuring entangled ribbons substructure. In order to establish suitable preparation and stability conditions, the assemblies were characterized in solution by UV-Vis spectroscopy, dynamic light scattering and $\zeta$-potential. The nanoparticles were tested against E. coli $\left(10^{6} \mathrm{CFU} /\right.$ $\mathrm{ml}$ ) in aqueous solution, showing a synergic activity of the heteropolyacid $\mathrm{H}_{5} \mathrm{PMo}_{10} \mathrm{~V}_{2} \mathrm{O}_{40}$ and CS. For such components, a highly porous and antibacterial film was obtained upon lyophilisation of the colloidal mixture.
\end{abstract}

Keywords Chitosan · Polyoxometalates - Nanoparticles · Antimicrobial activity · Porous film

Electronic supplementary material The online version of this article (doi:10.1007/s10876-013-0685-x) contains supplementary material, which is available to authorized users.

G. Fiorani · O. Saoncella · M. Bonchio · M. Carraro ( $₫)$

ITM-CNR and Department of Chemical Sciences, University of Padova, via F. Marzolo 1, 35131 Padua, Italy

e-mail: mauro.carraro@unipd.it

P. Kaner · S. A. Altinkaya $(\bowtie)$

Department of Chemical Engineering, Izmir Institute of Technology, Gulbahce Kampusu, 35430 Urla, Izmir, Turkey

e-mail: sacidealsoy@iyte.edu.tr

A. Figoli

ITM-CNR, Via P.Bucci, Cubo 17/C, 87030 Rende, CS, Italy 


\section{Introduction}

Polyoxometalates (POMs) are polyanionic oxides of early series transition metals which are characterized by an unmatched versatility in terms of structural features, resulting in a broad range of potential applications in catalysis, material science and medicine [1-3]. Thanks to their redox behavior, in particular, POMs have been extensively employed as catalysts for the oxidation of organic substrates and for the oxidative degradation of pollutants. Their bio-medical applications (antiviral, antitumoral, antibacterial) stem from the possibility to oxidize cellular components [4] and from their affinity towards biological molecules, which can be associated through electrostatic interactions [5].

The development of efficient antimicrobial systems containing POMs, suitable for water treatment, wound dressing and medical applications is an actual multidisciplinary challenge. Several different classes of POMs have been reported as efficient antimicrobial agents in a number of different formulations: polyoxotungstates were used to inhibit the growth of methicillin-resistant Staphylococcus aureus, since they depress the formation of a penicillin-binding protein with low affinity for $\beta$-lactams [6-9]. Then organoantimony(III)-containing heteropolytungstates were used against Escherichia coli and Bacillus subtilis, showing a slightly stronger activity against the latter gram-positive bacterium [10]. Polyoxovanadates were shown to affect membrane transport of potassium and organic substrates in Streptococcus pneumoniae [11], whereas nanocomposites containing polyoxomolybdates were successfully used against gram-negative and gram-positive bacteria [12-14].

Since POMs can interact with macromolecules, they can be loaded into biopolymers [15-17], including chitosan (CS) and its derivatives. CS is a linear polysaccharide constituted of $\beta-(1,4)$-D-glucosamine units, obtained from deacetylation of a naturally abundant biopolymer, chitin, which is the main constituent of the exoskeleton of crustaceans and cell wall of various fungi. Due to its availability, ease of preparation, excellent metal coordination [18] and particles stabilization capabilities [19, 20], CS has found application in various research field such as biomedical sciences [21-23], food preservation [24, 25] and water treatment [2631]. CS has been reported to suit water disinfection applications when incorporated into membranes, sponges, or surface coatings of water storage systems [31]. Because of its activity against bacteria, viruses and fungi, and its low toxicity towards animals and humans, CS is widely employed as a cheap and abundant antimicrobial agent $[32,33]$.

A key feature of $\mathrm{CS}$ is its polycationic nature at $\mathrm{pH}$ below its isoelectric point $(\mathrm{pKa}=6.28)$, due to the protonation of the amino groups at the $\mathrm{C}-2$ positions. This makes the biopolymer capable of promoting efficient electrostatic interaction with macromolecules (peptides and proteins, nucleic acids), viral capsids and negatively charged constituents on microorganism membranes [34]. Thanks to its preferential binding to lipopolysaccharidic domains of gram-negative bacteria surface, CS can compete with the binding sites of divalent cations, such as $\mathrm{Mg}^{2+}$ or $\mathrm{Ca}^{2+}$, leading to the disruption of outer membrane integrity, with permeabilization and leakage of intracellular components [35]. When POMs are mixed with CS in solution, the 
positively charged groups of CS associate with the polyanions surface [36]. In addition, terminal/bridging oxygen on POM surface may accept hydrogen bonds from $-\mathrm{OH}$ and $-\mathrm{NH}_{3}{ }^{+}$groups $[37,38]$. Such multiple intermolecular interactions result in the ionotropic gelation of the CS.

CS is therefore a promising candidate for the preparation of nanocomposites embedding negatively charged POMs. Among the examples, CS and its derivatives were used to encapsulate Eu [39, 40], Ti [41] or Co [42] substituted polyoxotungstates, so to enhance their cell-penetration, in order to develop nanomedicinal agents. In other cases, charged multilayered films of CS, and POMs were used as oxidation catalysts [43, 44], $\mathrm{H}_{2} \mathrm{O}_{2}$ sensors [45], electrocatalysts [46, 47] and for the preparation of luminescent films [47]. CS and decavanadate were employed in the fabrication of a composite material, which was integrated into wound dressings, showing antimicrobial activity against S. aureus [48] and E. coli [49]. Moreover, the redox active Keggin dodecamolybdate $\left[\mathrm{PMo}_{12} \mathrm{O}_{40}\right]^{3-}$ was incorporated into CS and used to inhibit E. coli [50].

This work reports the synthesis and characterization of novel nanocomposites derived from commercially available low molecular weight CS and different POMs, namely $\left(\mathrm{NH}_{4}\right)_{6} \mathrm{~V}_{10} \mathrm{O}_{28}\left(\mathbf{V}_{\mathbf{1 0}}\right)$ [51], $\mathrm{H}_{5} \mathrm{PMo}_{10} \mathrm{~V}_{2} \mathrm{O}_{40}\left(\mathbf{M o}_{\mathbf{1 0}} \mathbf{V}_{\mathbf{2}}\right)$ [52], $\mathrm{Na}_{4} \mathrm{~W}_{10} \mathrm{O}_{32}$ (Wo) [53] (i.e. representative vanadate, molybdate, tungstate precursors with recognized biological effects, antibacterial activity and/or oxidative capability) (Fig. 1).

The synthesis of CS/POM assemblies was optimized in order to obtain stable and discrete nanoparticles, with defined size distribution. In addition, tripolyphosphate (TPP) was added to promote the formation of CS nanoparticles through an analogue procedure [54, 55]. In order to produce an antimicrobial material for water disinfection, the resulting nanoparticles were preliminarily tested in solutions containing $E$. coli, showing, in one cases, a synergistic activity of the two domains. To expand the range of applicability of these hybrid nanocomposites, the active

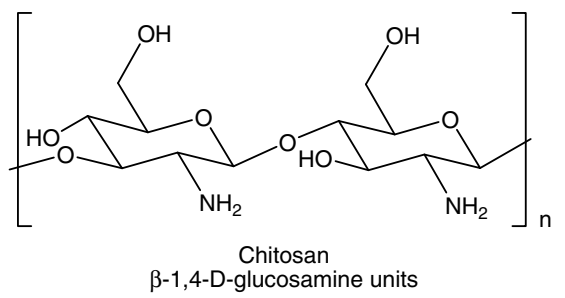

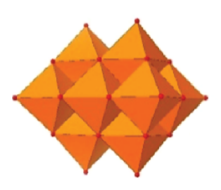

$\left[\mathrm{V}_{10} \mathrm{O}_{28}\right]^{6-}$

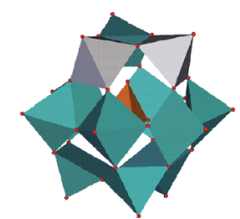

$\left[\mathrm{PMo}_{10} \mathrm{~V}_{2} \mathrm{O}_{40}\right]^{5-}$

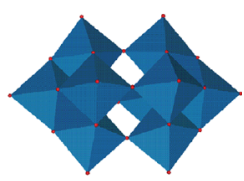

$\left[\mathrm{W}_{10} \mathrm{O}_{32}\right]^{4-}$

Fig. 1 Structures of chitosan and of the POMs used in this study 
components were then assembled in the form of an antibacterial and porous film. Perspectives for the preparation of a coating layer for water treatment purposes are finally herein discussed.

\section{Experiments}

\section{Materials}

Low molecular weight CS (40-90 kDa), TPP, hydroquinone (HQ) and $\beta$-nicotinamide adenine dinucleotide $(\mathrm{NADH})$ were purchased from commercial sources and used as received. POMs $\left(\mathrm{NH}_{4}\right)_{6} \mathrm{~V}_{10} \mathrm{O}_{28}$ [56], $\mathrm{H}_{5} \mathrm{PMo}_{10} \mathrm{~V}_{2} \mathrm{O}_{40}$ [57] and $\mathrm{Na}_{4} \mathrm{~W}_{10} \mathrm{O}_{32}$ [58] were synthesized according to reported literature procedures. Starting materials for POMs synthesis, $\mathrm{NH}_{4} \mathrm{VO}_{3}$ for $\left(\mathrm{NH}_{4}\right)_{6} \mathrm{~V}_{10} \mathrm{O}_{28}, \mathrm{Na}_{2} \mathrm{MoO}_{4} \cdot 2 \mathrm{H}_{2} \mathrm{O}$ and $\mathrm{Na}_{2} \mathrm{HPO}_{4} \cdot 12 \mathrm{H}_{2} \mathrm{O}$ for $\mathrm{H}_{5} \mathrm{PV}_{2} \mathrm{Mo}_{10} \mathrm{O}_{40}, \mathrm{Na}_{2} \mathrm{WO}_{4} \cdot 2 \mathrm{H}_{2} \mathrm{O}$ for $\mathrm{Na}_{4} \mathrm{~W}_{10} \mathrm{O}_{32}$, sodium hydroxide and glacial acetic acid were all available from commercial sources and used without further purification. All acidic and basic aqueous solution were prepared starting from reagent grade acids or alkali salts. Mueller-Hinton broth (OXOID), agar-agar (Sigma-Aldrich) and bacteriological peptone (OXOID) were used to carry out the antibacterial activity tests. E. coli (ATCC 25922) was chosen as the test microorganism. Deionized water was produced by a Sartorius Arium water purification system.

\section{Characterizations}

Fourier transform infrared (FT-IR) spectra were recorded with a Thermo Quest Nicolet 5700 spectrometer, preparing $\mathrm{KBr}$ pellets. Analytical samples were prepared by ultrafiltration of the nanoparticles solution with Millipore Amicon Centrifugal Units (MWCO $=50 \mathrm{KDa}$ ), centrifuging for $20 \mathrm{~min}$ at 3,800 rpm. UVVis spectra were recorded with cary 100 double beam UV-Vis spectrometers. Measurements were performed by using quartz cuvettes (1 $\mathrm{cm}$ optical path). Particle size and $\zeta$-potential were obtained by dynamic light scattering (DLS) measurements, with a Malvern Zetasizer Nano ZS90 instrument, in a quartz cuvette $(1 \mathrm{~cm}$ optical path) containing $1 \mathrm{ml}$ of the solution under investigation. For $\zeta$-potential measurements, polymethyl methacrylate cuvettes, purchased at Malvern, were used $(\mathrm{V}=1 \mathrm{ml})$.

${ }^{51} \mathrm{~V}$-NMR was performed on a Bruker AV 300, operating at $78.8 \mathrm{MHz}$, using freshly prepared $\left[\mathrm{V}(\mathrm{O})\left(\mathrm{O}_{2}\right)(\mathrm{pic})\left(\mathrm{H}_{2} \mathrm{O}\right)_{2}\right]$ (pic = picolinate) in $\mathrm{D}_{2} \mathrm{O} / \mathrm{H}_{2} \mathrm{O}$ at $\mathrm{pH} 1$ $\left(\mathrm{HClO}_{4}\right)$ as reference $(-600 \mathrm{ppm})$.

TEM images were obtained by drop casting the nanoparticles solution on copper grids (300 mesh). After removal of the excess water with paper, the grids were incubated with uranyl acetate (2\% in water). The samples were observed with a Tecnai G2 12 Twin Transmission Electron Microscopy (FEI Company).

Optical microscopy (OM) images were obtained on clean glass cover slips at room temperature by using an Olympus CX31 optical microscope fitted with Olympus DP25 digital camera. Micrographs were attained on E. coli samples incubated overnight at $37{ }^{\circ} \mathrm{C}$ in $\mathrm{CS} / \mathbf{M o}_{10} \mathbf{V}_{2}$ nanoparticles-combined broth, or in 
broth only, which were pipetted onto few drops of $0.1 \%(\mathrm{w})$ peptone water on clean glass cover slips for obtaining clear images.

Environmental scanning electron microscopy (ESEM) analyses were performed on a FEI Quanta 200 microscope equipped with EDAX and BSE detectors.

\section{Nanoparticles Preparation and Stability}

CS/POM NPs suspensions were prepared as follows: the amount of CS, required to obtain $1 \mathrm{mg} / \mathrm{ml}$ solution, was suspended in acetic acid $0.05 \% \mathrm{v} / \mathrm{v}$. The mixture was kept under vigorous stirring for $2 \mathrm{~h}$, until complete dissolution of CS. The solution was then filtered over polycarbonate hydrophilic isopore membrane ( $2 \mu \mathrm{m}$ cut-off), then $\mathrm{pH}$ was measured and adjusted to the desired value by dropwise addition of $1 \mathrm{M} \mathrm{NaOH}$. At the same time, aqueous POM solutions $(1 \mathrm{mg} / \mathrm{ml})$ were prepared. All solutions were sonicated for $30 \mathrm{~min}$. NPs were produced by dropwise addition of the required amount of POM solution to a known volume of CS solution, under stirring. Similarly, CS/POM/ TPP NPs were prepared by dropwise addition of the required amount of POM/TPP solution to a known volume of CS solution under stirring (concentration and weight ratios of the prepared nanocomposites are listed in Table S1).

The assembly efficiency was monitored by performing UV-Vis analysis of CS/ POM solutions before and after ultrafiltration (over Millipore Amicon ${ }^{\circledR}$ Ultra-15 centrifugal filter units, $\left.50 \mathrm{kDa} \mathrm{MWCO}, 4,000 \mathrm{rpm}, 20^{\prime}\right)$. Quantification was performed by using calibration curves of each POM. For all three POMs, the absorption spectra of the filtered solution shows a similar pattern, suggesting that the residual absorption was only due to the parts of CS that crossed the membrane.

POMs stability was evaluated by UV-Vis, upon comparison of their spectral features before and after permanence in aqueous solution for 7 days.

\section{Catalytic Tests}

The aerobic oxidation of NADH was monitored by measuring the variation of UVVis maximum absorbance of the reagent, at $\lambda=339 \mathrm{~nm}$. For this purpose, $2 \mathrm{ml}$ of aqueous substrate solution $(50 \mu \mathrm{M})$ were poured in a quartz cuvette, then dioxygen was bubbled for $2 \mathrm{~min}$ before POM or CS/POM addition (10\% mol of POM). Similarly, the aerobic oxidation of HQ was monitored by measuring the variation of $\mathrm{UV}-\mathrm{Vis}$ absorbance of the reagent, at $\lambda=245 \mathrm{~nm}$. $2 \mathrm{ml}$ of aqueous substrate solution $(0.18 \mathrm{mM})$ were poured inside a quartz cuvette, then dioxygen was bubbled for $2 \mathrm{~min}$ before POM or CS/POM addition (10\% mol of POM). All reactions were thermostated at $45^{\circ} \mathrm{C}$.

\section{Films Preparation}

CS-based films were prepared by lyophilization of $55 \mathrm{ml}$ of NPs solution, obtained from $5 \mathrm{ml}$ of $1 \mathrm{mg} / \mathrm{ml}$ aqueous solution of POM, added to $50 \mathrm{ml}$ of $1 \mathrm{mg} / \mathrm{ml} \mathrm{CS}$ in water (with $0.05 \%$ acetic acid).

For the preparation of the glycerol-stabilized film, a $1 \%(\mathrm{w} / \mathrm{v}) \mathrm{CS}$ solution in $1 \%$ acetic acid was prepared under stirring for $15 \mathrm{~min}$. Glycerol $(30 \% \mathrm{w} / \mathrm{w}$ with 
respect to CS) was then added. Stirring went on for $30 \mathrm{~min}$, so to obtain the total homogenization of the mixture. Finally, the volume of $\mathbf{P M \mathbf { o } _ { 1 0 }} \mathbf{V}_{\mathbf{2}}(1 \mathrm{mg} / \mathrm{ml}$ aqueous solution), required to obtain a final 10:1 (CS/POM, w/w) ratio, was quickly added to the CS/glycerol solution. The resulting mixture was poured in a petri dish, and evaporated to dryness at room temperature for 3 days.

Antibacterial Tests

Antibacterial tests were performed on E. coli bacteria strains. Muller-Hinton (MH) broth and $\mathrm{MH}$ agar were used as growth media. E. coli was inoculated onto agar and incubated for $18 \mathrm{~h}$ at $37^{\circ} \mathrm{C}$ for the activation of bacteria. After incubation, the initial E. coli concentration was adjusted by picking off bacteria colonies with a swap from the $\mathrm{MH}$ agar plate and mixing them with $0.1 \% \mathrm{w} / \mathrm{w}$ peptone water, till they reached a Mc Farland value of 0.5 , which corresponds to approximately $10^{8}$ Colony Forming Units per $\mathrm{ml}(\mathrm{CFU} / \mathrm{ml})$.

All the materials were sterilized at standard conditions, i.e. $120{ }^{\circ} \mathrm{C}, 15 \mathrm{psi}$ and for $30^{\prime}$ before use. Different concentrations of CS NPs, $0.6,0.5$ and $0.3 \mathrm{mg} / \mathrm{ml}$, were tested against E. coli. For this purpose, $100 \mu \mathrm{l}$ of the $E$. coli solution were added into $10 \mathrm{ml}$ of $\mathrm{CS}$ nanoaggregates containing $\mathrm{MH}$ broth to reach an initial bacteria concentration of $\sim 10^{6} \mathrm{CFU} / \mathrm{ml}$ in sterilized tubes, and were further incubated at $37{ }^{\circ} \mathrm{C}$ for $24 \mathrm{~h}$. Control samples of $\mathrm{MH}$ broth $(10 \mathrm{ml})$ containing only E. coli $(100 \mu \mathrm{l})$ were prepared. Five replicates of each sample were prepared for the tests, so to provide statistical confidence. After incubation, the sample solutions were serially diluted over anticipated orders of magnitude and $100 \mu \mathrm{l}$ samples were plated onto triplicate $\mathrm{MH}$ agar plates using pour-plate method. The plated petri dishes were further incubated at $37{ }^{\circ} \mathrm{C}$ for $24 \mathrm{~h}$. After incubation, colonies formed on plates were counted and the microbial counts in the original tubes prior to dilution were calculated as CFU/ml. The antibacterial activity of CS NPs was measured as the reduction in number of colonies for CS NPs-treated samples in comparison to the untreated control sample.

For evaluating the antibacterial properties of film samples, an E. coli solution in $\mathrm{MH}$ broth was serially diluted with $\mathrm{MH}$ broth to $100 \mathrm{CFU} / \mathrm{ml}$ from a stock of $10^{6} \mathrm{CFU} /$ $\mathrm{ml}$. Subsequently, $0.6 \mathrm{ml}$ of the diluted solution, which corresponds to $60 \mathrm{CFU}$, were spread onto the films. Prior to overnight incubation at $37{ }^{\circ} \mathrm{C}$ on $\mathrm{MH}$ agar plates, films were subjected to $3 \mathrm{~h}$ of preincubation (which involves waiting for complete absorption of bacteria solution on film surface at room temperature before imprinting them on $\mathrm{MH}$ agar plates). After $24 \mathrm{~h}$ incubation period had elapsed, the number of bacteria present on the film surface was compared to the initial $60 \mathrm{CFU} / \mathrm{ml}$ seeded.

\section{Results and Discussion}

Nanoparticles Characterization

CS/POM and CS/POM/TPP nanoparticles were prepared by exploiting electrostatic interactions of the oppositely charged building blocks, i.e. by mixing aqueous 
solutions containing the polycation (CS) and the appropriate polyanion, optimizing the procedure for three different POMs. In order to obtain nanoaggregates featuring homogeneous size distribution, different preparation routes were explored. DLS analysis and $\zeta$-potential measurements were conducted to monitor the influence of $\mathrm{pH}$ and of the ratio between polycation and polyanion concentrations, on the observed hydrodynamic diameter and polydispersity index (PDI). The effect of $\mathrm{pH}$ on NPs size was initially verified by preparing CS/POM assemblies at a fixed CS/ POM ratio (10:1 w/w) and at different $\mathrm{pH}$ values $(3.7,4.9$ and 6.0$)$, so to establish suitable conditions for obtaining smaller particles with low size dispersion. Average NP diameters were found between 100 and $420 \mathrm{~nm}$ (Table S2). For the three different CS/POM combinations, the average particle size measured was generally higher at lower $\mathrm{pH}$, ranging from $160 \mathrm{~nm}$ for $\mathbf{M o}_{\mathbf{1 0}} \mathbf{V}_{\mathbf{2}}$ to $420 \mathrm{~nm}$ for $\mathbf{V}_{\mathbf{1 0}}$ $(\mathrm{pH}=3.7)$, whereas, at higher $\mathrm{pH}$, the size range was narrower $(105-175 \mathrm{~nm}$ at $\mathrm{pH}=6.0$, Table S2 and Fig. S1). This behavior is in agreement with DLS analysis of acidic CS solutions: the overall positive charge of CS strands increases at lower $\mathrm{pH}$, making the macromolecules more rigid, due to intramolecular repulsions, thus increasing their hydrodynamic radius [59]. In addition, although the measured PDI values did not display a linear behavior as a function of the $\mathrm{pH}$, they were found to be lower at $\mathrm{pH} \sim 6$ for all CS/POM (0.36-0.46, Table S2).

NPs with different CS/POM (from 50:1 to 5:1) weight ratio were thus prepared at $\mathrm{pH}=6.0$ and characterized by DLS to evaluate the effect of POM loading on the resulting NPs. For $\mathbf{M o}_{\mathbf{1 0}} \mathbf{V}_{\mathbf{2}}$ and $\mathbf{W}_{\mathbf{1 0}}$, larger particles (430-490 nm) were obtained at low POM content (CS/POM 50:1 w/w). An opposite trend was observed with $\mathbf{V}_{\mathbf{1 0}}$, for which a narrower size range (188-235 nm) was observed. A ratio CS/POM 10:1 w/w was hence adopted to provide smaller particles with high loading (Table 1).

In order to evaluate assembly features and colloidal stability of the NPs with different formulation, $\zeta$-potential measurements were performed in aqueous solution, including the analysis of the isolated CS and POM at different $\mathrm{pH}$. For CS, the observed $\zeta$-potential was in agreement with literature data, yielding a

Table 1 Effect of CS:POM ratio on size and PDI of NPs prepared at $\mathrm{pH} 6$

\begin{tabular}{lllllc}
\hline$\#$ & $\begin{array}{l}\text { CS:POM } \\
(\mathrm{w} / \mathrm{w})\end{array}$ & POM & $\begin{array}{l}\text { Diameter } \\
(\mathrm{nm})\end{array}$ & PDI & $\begin{array}{c}\zeta \text {-potential } \\
(\mathrm{mV})\end{array}$ \\
\hline 1 & $50: 1$ & $\mathbf{M o}_{\mathbf{1 0}} \mathbf{V}_{\mathbf{2}}$ & 430 & 0.56 & 32 \\
2 & $10: 1$ & $\mathbf{M o}_{\mathbf{1 0}} \mathbf{V}_{\mathbf{2}}$ & 220 & 0.48 & 24 \\
3 & $5: 1$ & $\mathbf{M o}_{\mathbf{1 0}} \mathbf{V}_{\mathbf{2}}$ & 254 & 0.49 & 32 \\
4 & $50: 1$ & $\mathbf{W}_{\mathbf{1 0}}$ & 490 & 0.48 & 32 \\
5 & $10: 1$ & $\mathbf{W}_{\mathbf{1 0}}$ & 175 & 0.42 & 22 \\
6 & $5: 1$ & $\mathbf{W}_{\mathbf{1 0}}$ & 246 & 0.42 & 26 \\
7 & $50: 1$ & $\mathbf{V}_{\mathbf{1 0}}$ & 188 & 0.52 & 26 \\
8 & $10: 1$ & $\mathbf{V}_{\mathbf{1 0}}$ & 220 & 0.38 & 18 \\
9 & $5: 1$ & $\mathbf{V}_{\mathbf{1 0}}$ & 235 & 0.32 & 5 \\
\hline
\end{tabular}


positive potential of $26 \mathrm{mV}$ [60]. Negative $\zeta$-potential values were observed for the three POMs, in all the $\mathrm{pH}$ range explored, with values between -9 and $-40 \mathrm{mV}$ (Fig. S2). Such broad range may be due to counterion-mediated attraction between the polyanions, which results in a partial charge shielding [61]. In addition, the wider $\zeta$-potential range observed for $\mathbf{V}_{\mathbf{1 0}}$ is likely to result from equilibria involving the formation of lower nuclearity oxovanadates $\left(\mathrm{V}_{1}-\mathrm{V}_{5}\right)$ at higher $\mathrm{pH}[62]$.

$\zeta$-potential measurements obtained from freshly prepared CS/POMs solutions gave positive values in all cases (Fig. S3 and Table 1). For CS/Mo $\mathbf{M o}_{\mathbf{1 0}} \mathbf{V}_{\mathbf{2}}$ and CS/ $\mathbf{W}_{\mathbf{1 0}}$, in particular, the observed values are similar or even higher than that of the CS at $\mathrm{pH}=6$, suggesting that the POMs are fully encapsulated into the NPs, with small effects on the surface charge density of the particles. In such conditions, the repulsion potential between the aggregates seems to be large enough to prevent their fast coalescence and flocculation, without needing any undesired surfactant [63]. In the case of $\mathbf{V}_{\mathbf{1 0}}$, the decrease in the observed $\zeta$-potential absolute value is consistent with NPs bearing surface exposed oxovanadates. ${ }^{1}$ Ammonium ions may contribute to such behaviour, establishing additional weak interactions between the polyanions and CS. The low $\zeta$-potential of these particles is likely responsible for the opposite dimension trend (Table 1).

\section{POM Encapsulation Efficiency and NPs Stability}

The encapsulation efficiency of the resulting CS/POM nanocomposites was evaluated by UV-Vis analysis of the CS/POM solution before and after ultrafiltration. Data were calculated by the UV-Vis measurement in the interval 245-277 nm, where the POMs show absorbance peaks (Fig. S4-S6). The encapsulation percentage was high (88-99 \%, see Table S3), especially for $\mathbf{W}_{\mathbf{1 0}}$ (Fig. S6), suggesting an efficient interaction between the POMs and CS charged domains. The same procedure was applied to evaluate the encapsulation efficiency into CS in the presence of TPP. For all three POMs, NPs were prepared adding a solution of POM and TPP in ratio of 5:2 (w/w) to a solution of CS $0.05 \%(\mathrm{w} / \mathrm{v})$. The encapsulation efficiency turned out to be higher than $82 \%$ in all cases, as shown by the UV-Vis spectra (Fig. S7-S9 and Table S3). However, a decreased encapsulation efficiency was observed for all the TPP based NPs, particularly for $\mathbf{V}_{10}$ and $\mathbf{W}_{10}$ containing NPs. This behaviour is ascribable to the competition between the polyanionic species (POM and TPP) in the NPs formation process.

Modification of the NPs components was evaluated by UV-Vis measurements on aqueous solutions containing the solute of interest, over several days. In none of the cases a significant change in the absorption spectra was observed (Fig. S10-S12). $\mathrm{CS} / \mathrm{Mo}_{10} \mathbf{V}_{2}$ NPs stability was further studied by UV-Vis spectroscopy and DLS. After $24 \mathrm{~h}$, we observed a $30 \%$ increase in diameter and a lowering of $\zeta$-potential

\footnotetext{
${ }^{1}$ In the presence of a small amount of CS, $\mathbf{M o}_{\mathbf{1 0}} \mathbf{V}_{\mathbf{2}}$ and $\mathbf{V}_{\mathbf{1 0}}$ gave very broad ${ }^{51} \mathrm{~V}$-NMR signals centred, respectively, at -500 and $-550 \mathrm{ppm}$. The latter value is in agreement with the occurrence of $\mathrm{V}_{1}-\mathrm{V}_{5}$ oxospecies [62].
} 
(from -24 to $-31 \mathrm{mV}$ ). POM release in water was however excluded by checking of ultrafiltered surnatant solutions, since POM absorbance was not detected.

\section{Electronic Microscopy}

CS/POM NPs morphology was characterized by transmission electron microscopy (TEM). The images (Fig. 2) show nanoaggregates in the range of hundred $\mathrm{nm}$, without any evidence of phase separation. In all cases, NPs with irregular shapes were observed, while the different dimensions observed in solution (DLS) and at the solid state are likely due to the instability of the assemblies under vacuum condition required for TEM analyses. Bundles with ribbon-like substructure, which are particularly defined for $\mathrm{CS} / \mathbf{V}_{\mathbf{1 0}}$, can be observed. This behaviour is different from that observed with other procedures, that led to spherical POM/CS nanoparticles $[38,40]$.

For all compositions, TPP has a minor effect in improving the aggregation (Fig. S13-S15), while, in the absence of POMs, CS/TPP nanoparticles were irregularly shaped, lacking in defined substructural features (Fig. S16).

\section{Antimicrobial Activity}

The antibacterial activities of the CS NPs prepared at $\mathrm{pH} 6$ by using TPP (CS/ $\mathrm{TPP}=50: 2 \mathrm{w} / \mathrm{w}), \mathrm{POM}(\mathrm{CS} / \mathrm{POM}=10: 1 \mathrm{w} / \mathrm{w})$ or a combination of both $(\mathrm{CS} / \mathrm{TPP} /$ $\mathrm{POM}=50: 5: 2 \mathrm{w} / \mathrm{w}$ ) were tested against $E$. coli (ATCC 25922). In addition, CS (at $\mathrm{pH}=6$ ) and $\mathbf{M o}_{10} \mathbf{V}_{\mathbf{2}}$ were tested separately to prove their individual antibacterial activity. Results were compared to a control case assay of untreated E. coli bacteria. CS NPs were added to provide a POM concentration between 0.6 and $0.3 \mathrm{mg} / \mathrm{ml}$. $\mathbf{M o}_{10} \mathbf{V}_{2}$ solution was employed at $0.6 \mathrm{mg} / \mathrm{ml}$ dose only, while CS was added in a concentration corresponding to that required to achieve the $0.6 \mathrm{mg} / \mathrm{ml} \mathrm{dose}$. The results of antibacterial activity tests are summarized in Fig. 3 and in Table S4. A dose-dependent effect on bacteria inhibition was observed for all the NPs solutions tested. The best results were obtained at $0.6 \mathrm{mg} / \mathrm{ml}$, the highest applied dose: CS/ $\mathbf{M o}_{10} \mathbf{V}_{2}$ and CS/TPP/Mo10 $\mathbf{V}_{2}$ nanoparticles completely inhibited bacterial growth, $\mathrm{CS} / \mathrm{TPP}$ resulted in eightfold decrease in bacteria count, while $\mathrm{CS} / \mathbf{W}_{\mathbf{1 0}}$ and $\mathrm{CS} / \mathbf{V}_{\mathbf{1 0}}$

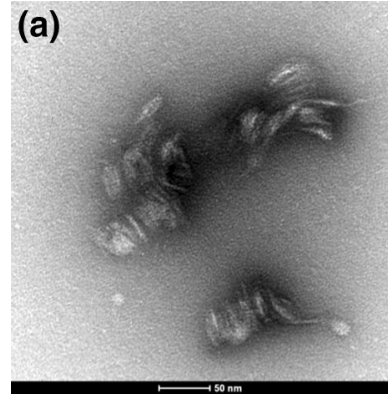

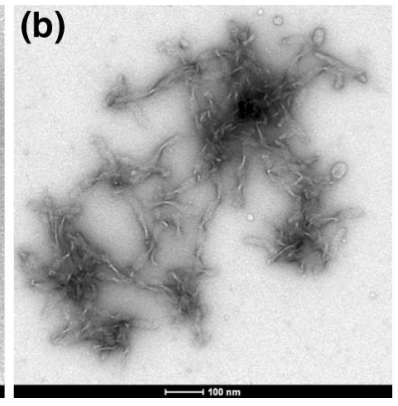

(c)

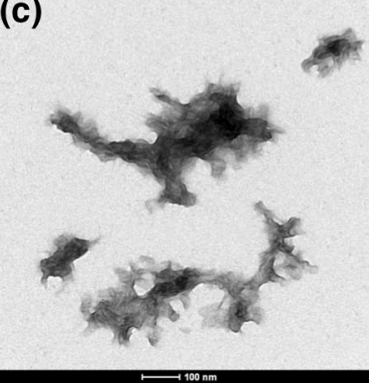

Fig. 2 TEM images of NPs of CS/Mo $/ \mathbf{M o}_{\mathbf{1 0}}, \mathrm{CS} / \mathbf{V}_{\mathbf{1 0}}, \mathrm{CS} / \mathbf{W}_{\mathbf{1 0}}(\mathrm{CS} / \mathrm{POM}=10: 1)$ 
NPs led to sevenfold decrease. The antibacterial effect of CS/Mo $\mathbf{M}_{\mathbf{1 0}} \mathbf{V}_{\mathbf{2}}$ nanoparticles at $0.6 \mathrm{mg} / \mathrm{ml}$ highlights the synergistic antimicrobial activity of CS and $\mathbf{M o}_{\mathbf{1 0}} \mathbf{V}_{\mathbf{2}}$, since the separate components did not display the same effect, causing only seven and sixfold declines in bacteria count, respectively (Fig. 3). At $0.5 \mathrm{mg} / \mathrm{ml} \mathrm{dose,} \mathrm{all}$ the NPs studied displayed a lower antibacterial activity. Antibacterial activities of $\mathrm{CS} / \mathbf{M o}_{10} \mathbf{V}_{2}, \mathrm{CS} / \mathbf{W}_{10}$ and $\mathrm{CS} / \mathrm{TPP} / \mathbf{M o}_{10} \mathbf{V}_{2}$ nanoparticles were almost the same at this dose, resulting in sevenfold reduction on average, and higher compared to CS/ TPP and CS/ $\mathbf{V}_{10}$ agents, both of which cause threefold reduction in bacteria count. At a $0.3 \mathrm{mg} / \mathrm{ml}$ dosage, bacterial growth was scarcely inhibited by adding NPs, even if the highest antibacterial activity was still observed with $\mathrm{CS} / \mathbf{M o}_{\mathbf{1 0}} \mathbf{V}_{\mathbf{2}}$ nanoparticles, which caused a twofold reduction.

The optical microscope observations of E. coli incubated overnight at $37{ }^{\circ} \mathrm{C}$ with $\mathrm{CS} / \mathbf{M o}_{10} \mathbf{V}_{2}$ nanoparticles are reported in Fig. S17. The extensive degradation of the microorganisms is witnessed by the disruption of their rod-shaped morphology, resulting in their precipitation in the form of distinctive clusters.

Variations in parameters such as the average molecular weight of CS, the type of cross-linking agent, the average nanoparticle size $(\mathrm{nm})$ and the nanoparticle surface charge $(\mathrm{mV})$ strongly affect the antibacterial activities of CS NPs [64-67]. Concerning CS/POM composites, Chen et al. [49] found that $\mathbf{V}_{\mathbf{1 0}} / \mathrm{Ca}^{2+} / \mathrm{CS}$ membranes display improved antibacterial activity with respect to the isolated components $\mathrm{CS}$ and $\mathrm{V}_{10} \mathrm{O}_{68}{ }^{6-}$. However, the different state of POM (amorphous crystals of $\mathrm{Ca}^{2+}$ salt of $\mathbf{V}_{\mathbf{1 0}}$, featuring size smaller than $50 \mathrm{~nm}$ ) led to specific

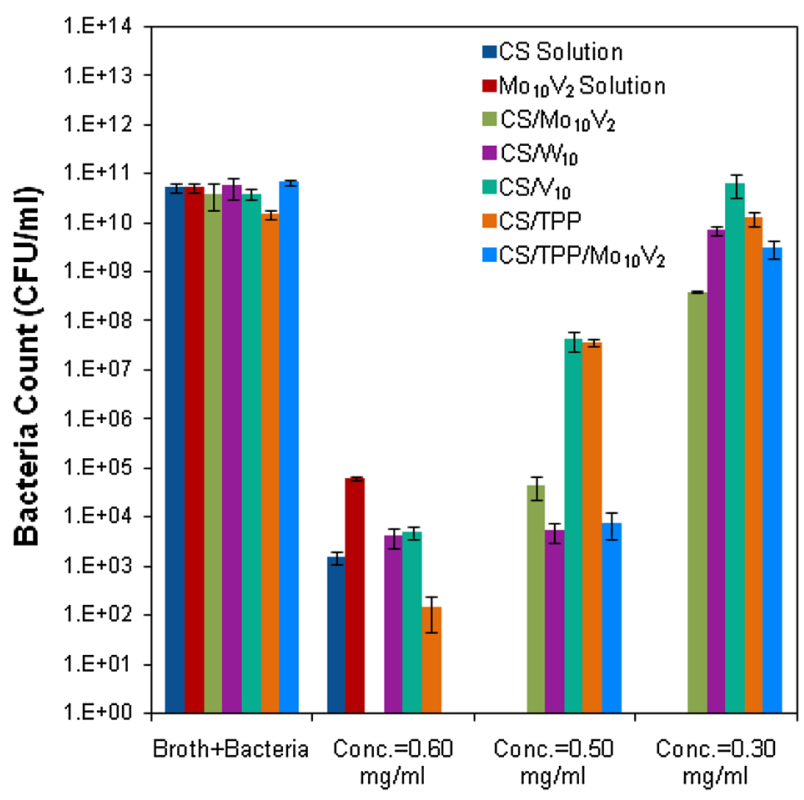

Fig. 3 Bacteria count at different concentration of antimicrobial agents. Antibacterial activity is expressed as the decrease in number of E. coli colony-forming units (CFU/ml) compared to the control case, following overnight incubation 
distinct properties of the resulting assembly, pointing out the significance of the conditions adopted in the synthesis.

Among several mechanisms proposed for antimicrobial activities of metal/metal oxides, impairment of membrane architecture through electrostatic repulsion [13] and oxidative degradation have been commonly acknowledged [68]. As a matter of fact, POMs have already been used to promote electron transfer (ET) reactions with biologically relevant substrates, highlighting their major role as electron acceptors [6]. The oxidative power of the POMs under investigation is thus expected to be a key factor for better performances. The ET activity of the title POMs was evaluated in aqueous environment, with or without $\mathrm{CS}$, by performing the aerobic oxidation of reduced $\beta$-nicotinamide adenine dinucleotide (NADH) and HQ. NADH and its oxidized form $\left(\mathrm{NAD}^{+}\right)$are coenzymes that play an essential role in metabolism as electron carriers [69]. As a result $\mathrm{NADH}\left(\mathrm{E}^{0}=-0.32 \mathrm{~V}\right.$ vs $\left.\mathrm{NHE}\right)$ is smoothly oxidized by all POMs, with conversion of 70-83\% in $10 \mathrm{~h}$ (Fig. 4) [70-73]. Moreover, $\mathbf{M o}_{\mathbf{1 0}} \mathbf{V}_{\mathbf{2}}$ into CS is still able to oxidize NADH (83\% conversion in $10 \mathrm{~h})$.

HQ has been chosen as a model substrate of reduced ubiquinone, a molecule involved in the respiratory chain. At $\mathrm{pH}=6$, HQ can be oxidized $\left(\mathrm{E}^{0}=0.7 \mathrm{~V}\right.$ vs $\mathrm{NHE}$ ) by the POMs to its corresponding dicarbonyl product, $p$-benzoquinone (BQ) $[74,75]$, whereby dioxygen is responsible for catalyst re-oxidation [76]. Because of its higher reduction potential, only $\mathbf{M o}_{\mathbf{1 0}} \mathbf{V}_{\mathbf{2}}\left(\mathrm{E}^{0}=0.7 \mathrm{~V}\right.$ vs NHE) converts HQ into BQ $(27 \%$ yield in $15 \mathrm{~h})$, upon reduction of $\mathrm{V}(\mathrm{V})$ ions to $\mathrm{V}(\mathrm{IV})$ [77, 78]. In this case, the reaction by CS/Mo $\mathbf{M o}_{10} \mathbf{V}_{2}$ was slower (6\% yield in 15 h, Fig. S18-S19).

Considering this scenario, the enhanced efficiency of CS/POM likely benefits from the attractive forces between positively charged CS and negatively charged membrane components [36]: beside causing outer membrane permeabilization, CS guarantees the contact between the POM and the membrane. The lower antibacterial activity displayed by $\mathrm{CS} / \mathbf{V}_{\mathbf{1 0}}$ nanoparticles can thus be explained by their decreased $\zeta$-potential, in comparison to the other nanoparticles, including CS/TPP. This finding is in agreement with the work of Du et al. [79], who studied CS
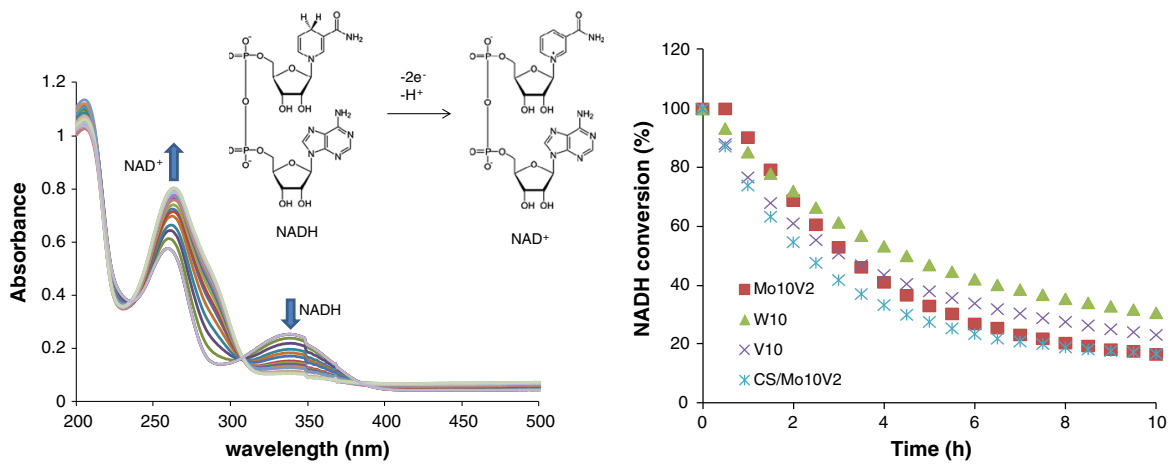

Fig. 4 Oxidation scheme of $\mathrm{NADH}(50 \mu \mathrm{M}$ in water) and UV-Vis spectra collected during the reaction in the presence of $10 \% \mathrm{~mol} \mathbf{M o}_{10} \mathbf{V}_{2}$, at $45{ }^{\circ} \mathrm{C}$; kinetic traces were obtained monitoring the absorbance at $339 \mathrm{~nm}$. In the absence of POMs, $43 \% \mathrm{NADH}$ was oxidized in $10 \mathrm{~h}$ 
nanoparticles loaded with different metal ions and concluded that the antibacterial activity is directly correlated with the $\zeta$-potential of resulting nanoparticles. Then it was demonstrated that size and shape of nanoparticles may lead to differences in contact area, significantly altering the antimicrobial activity. In fact, smaller metal nanoparticles showed enhanced antimicrobial properties toward E. coli than larger particles, due to their larger contact surface area (compared to the volume) $[65,80]$. In addition, the flexible shape of CS nanoaggregates, with respect to other nanoparticles, may guarantee a better contact with bacterial membrane. TEM images (Fig. 2), stress out the relatively small size and irregular shape of CS/ $\mathbf{M o}_{10} \mathbf{V}_{2}$ nanoparticles, matching these requirements.

\section{Preparation of an Antimicrobial Film}

$\mathrm{CS} / \mathbf{M o}_{10} \mathbf{V}_{2}$ NPs shows antibacterial activity at high doses. Nevertheless, such hybrid assembly is expected to benefit from material design [14, 81-83], immobilization on solid substrates [84] and cross-linking [85, 86]. The specimens were thus lyophilized to obtain composite films, which were analyzed at the solid state by ESEM. The microscopy shows a network of fibers (Fig. 5, S21, S24), likely resulting from the growth of the nano-ribbons shaped structures. While the POMfree CS is richer in film-like regions (Fig. S20), the cross-linking effect of the POMs is more evident for $\mathrm{CS} / \mathbf{M o}_{10} \mathbf{V}_{\mathbf{2}}$, which is characterized by a homogeneous network of fibers (with length upto hundreds of $\mu \mathrm{m}$ ), with a diameter between 2 and $12 \mu \mathrm{m}$, in agreement with an efficient cross-linking effect of the polyanion. EDAX (Energy dispersive X-ray spectroscopy) microanalysis confirmed the material composition (Fig. S22, S25 and S28), with no phase separation. The strong contrast observed by TEM is in agreement with an even POM distribution throughout the fibers (Fig. S27).

In addition, polyanions bands can be detected by FT-IR spectroscopy in the region between 600 and $1,050 \mathrm{~cm}^{-1}$ (Fig. S23, S26, S29). At variance with previously reported CS/POM films, these exhibit high porosity, flexibility and complete embedding of the POM [41, 45, 49, 87, 88]. Since the hybrid materials is insoluble and does not show POM leaching, it is promising for the development of porous antimicrobial coatings for water treatments.

In order to evaluate the antibacterial properties of the solid CS/Mo $\mathbf{M o}_{\mathbf{1 0}} \mathbf{V}_{\mathbf{2}}$ sample, an $E$. coli solution including $60 \mathrm{CFU} / \mathrm{ml}$ was spread onto the films. After overnight incubation at $37{ }^{\circ} \mathrm{C}$, bacteria growth was completely inhibited on film surface, while the CS sample surface was covered with bacteria, manifesting that a strong antibacterial activity is imparted to the film only when CS is loaded with $\mathbf{M o}_{\mathbf{1 0}} \mathbf{V}_{\mathbf{2}}$.

Finally, a preliminary test for the development of mechanically resistant films of $\mathrm{CS} / \mathrm{Mo}_{10} \mathrm{~V}_{2}$, containing glycerol as plasticizer additive, was undertaken [89]. Glycerol is indeed expected to foster further cross-linking between carbohydrate chains through hydrogen bonding. The resulting dense and homogeneous film, with $30 \mu \mathrm{m}$ thickness (Fig. S30), however, did not inhibit the E. coli bacteria growth completely, strengthening the superior performances of CS/POM in the form of a flexible and porous structure. Further experiments will be aimed at tuning 

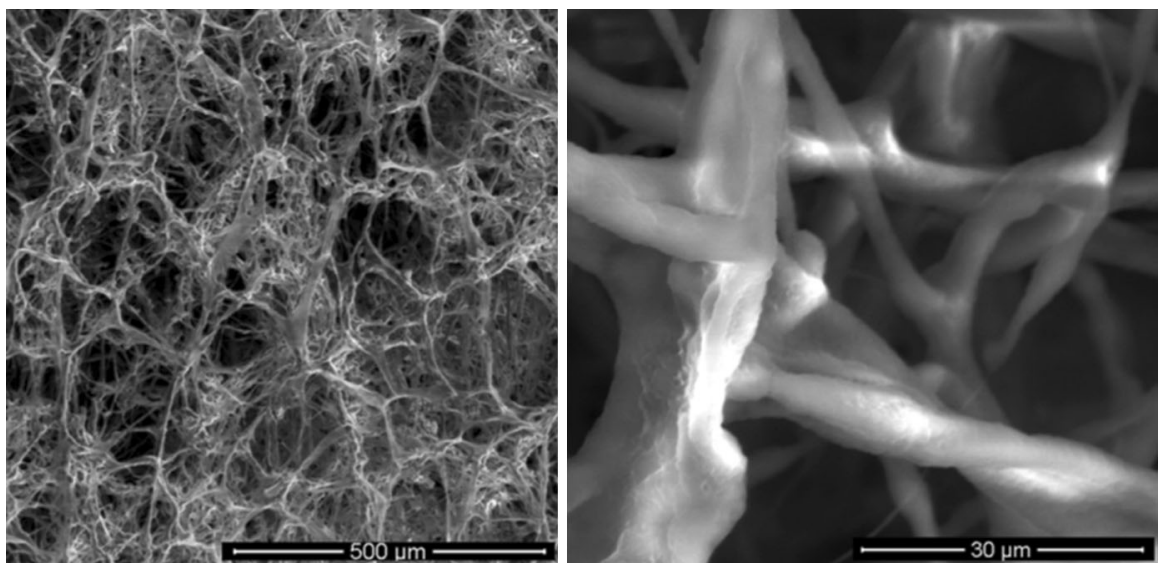

Fig. 5 ESEM images of a lyophilized sample of CS/Mo $\mathbf{M o}_{\mathbf{1 0}} \mathbf{V}_{\mathbf{2}}$

mechanical properties and testing filtrating capabilities of the composite films, upon addition of different cross-linking agents.

\section{Conclusions}

A series of organic-inorganic nanomaterials based on CS and different POMs were prepared and characterized in order to establish suitable conditions for obtaining small NPs featuring high POM loading. Our results point to investigate the performance of the composite material against E. coli (gram negative bacterium), demonstrating the key role of both components to enhance the activity. The best antibacterial activity was obtained with the NPs prepared by using $\mathrm{H}_{5} \mathrm{PV}_{2} \mathrm{Mo}_{10} \mathrm{O}_{40}$ as crosslinking agent. The synergic activity of CS and the molybdovanadate likely springs from CS-mediated membrane destabilization, coupled with POM-mediated oxidation of substrates involved in the electron transport chain. Such multiple degradation effects lead to lethal cell damages, as demonstrated by the loss of rodshape morphology and the decrease of viable counts.

The most efficient composite can be prepared in the form of a stable film, without affecting the observed antimicrobial power. In this case, the synergistic activity of the two components was even more important. Performances of the porous film will be evaluated upon integration into a water treatment device.

Acknowledgments The research leading to these results has received funding from the European Union's Seventh Framework Programme (FP7/2007-2013) under grant agreement n²46039 and from MIUR (FIRB prot. RBAP11ETKA). We would like to thank the Biotechnology and Bioengineering Application and Research Center staff at the Izmir Institute of Technology for their kind help and technical support. We also thank Dr. Claudio Furlan, CUGAS-University of Padova, for ESEM and EDAX analyses, and Dr. Federico Caicci, Biology Department, University of Padova, for TEM analysis. 


\section{References}

1. Polyoxometalates Cluster Science Issue, U. Kortz and T. Liu (guest eds), (2013). Eur. J. Inorg. Chem. 2013, 7325.

2. D. L. Long, E. Burkholder, and L. Cronin (2007). Chem. Soc. Rev. 36, 105.

3. M. T. Pope and A. Müller (1991). Angew. Chem. Int. Ed. 30, 34.

4. J. T. Rhule, C. L. Hill, and D. A. Judd (1998). Chem. Rev. 98, 327.

5. H. Stephan, M. Kubeil, F. Emmerling, and C. E. Muller (2013). Eur. J. Inorg. Chem. 2013, 1585.

6. P. Sami, T. D. Anand, M. Premanathan, and K. Rajasekaran (2010). Transition Met. Chem. 35, 1019.

7. T. Yamase, N. Fukuda, and Y. Tajima (1996). Biol. Pharm. Bull. 19, 459.

8. N. Fukuda, T. Yamase, and Y. Tajima (1999). Biol. Pharm. Bull. 22, 463.

9. M. Inoue, T. Suzuki, Y. Fujita, M. Oda, N. Matsumoto, and T. Yamase (2006). J. Inorg. Biochem. 100, 1225.

10. M. Barsukova-Stuckart, L. F. Piedra-Garza, B. Gautam, G. Alfaro-Espinoza, N. V. Izarova, A. Banerjee, B. S. Bassil, M. S. Ullrich, H. J. Breunig, C. Silvestru, and U. Kortz (2012). Inorg. Chem. 51, 12015.

11. N. Fukuda and T. Yamase (1997). Biol. Pharm. Bull. 20, 927.

12. Y. M. Kong, L. N. Pan, J. Peng, B. Xue, J. Lu, and B. X. Dong (2007). Mater. Lett. $61,2393$.

13. F.-C. Yang, K.-H. Wu, W.-P. Lin, and M.-K. Hu (2009). Microporous Mesoporous Mater. $118,467$.

14. K. H. Wu, P. Y. Yu, C. C. Yang, G. P. Wang, and C. M. Chao (2009). Polym. Degrad. Stab. 94, 1411.

15. F. Carn, N. Steunou, M. Djabourov, T. Coradin, F. Ribot, and J. Livage (2008). Soft Matter 4, 735.

16. K. I. Draget, K. M. Varum, E. Moen, H. Gynnild, and O. Smidsrod (1992). Biomaterials 13, 635.

17. E. Guibal (2004). Sep. Purif. Technol. 38, 43.

18. R. Guo, Y. Cheng, D. Ding, X. L. Li, L. Y. Zhang, X. Q. Jiang, and B. R. Liu (2011). Macromol. Biosci. 11, 839.

19. A. J. Varma, S. V. Deshpande, and J. F. Kennedy (2004). Carbohydr. Polym. 55, 77.

20. E. Guibal (2005). Prog. Polym. Sci. 30, 71.

21. D. J. Macquarrie and J. J. E. Hardy (2005). Ind. Eng. Chem. Res. 44, 8499.

22. R. A. A. Muzzarelli (2009). Carbohydr. Polym. 76, 167.

23. H. Peniche and C. Peniche (2011). Polym. Int. 60, 883.

24. J. K. F. Suh and H. W. T. Matthew (2000). Biomaterials 21, 2589.

25. R. A. A. Muzzarelli (1996). Carbohydr. Polym. 29, 309.

26. S. Roller and N. Covill (1999). Int. J. Food Microbiol. 47, 67.

27. S. E. Bailey, T. J. Olin, R. M. Bricka, and D. D. Adrian (1999). Water Res. 33, 2469.

28. A. Bhatnagar and M. Sillanpää (2009). Adv. Colloid Interface Sci. 152, 26.

29. G. Crini (2005). Prog. Polym. Sci. 30, 38.

30. L. Dambies, T. Vincent, A. Domard, and E. Guibal (2001). Biomacromolecules 2, 1198.

31. Q. L. Li, S. Mahendra, D. Y. Lyon, L. Brunet, M. V. Liga, D. Li, and P. J. J. Alvarez (2008). Water Res. 42, 4591.

32. J. Vinšová and E. Vavř́ḱková (2011). Curr. Pharm. Design 17, 3596.

33. G. Geisberger, E. B. Gyenge, D. Hinger, A. Kach, C. Maake, and G. R. Patzke (2013). Biomacromolecules 14, 1010.

34. E. I. Rabea, M. E. T. Badawy, C. V. Stevens, G. Smagghe, and W. Steurbaut (2003). Biomacromolecules 4, 1457.

35. N. R. Sudarshan, D. G. Hoover, and D. Knorr (1992). Food Biotechnol. 6, 257.

36. D. Raafat and H. G. Sahl (2009). Microb. Biotech. 2, 186.

37. H. Tang, P. Zhang, T. L. Kieft, S. J. Ryan, S. M. Baker, W. P. Wiesmann, and S. Rogelj (2010). Acta Biomaterialia 6, 2562.

38. T. Meissner, R. Bergmann, J. Oswald, K. Rode, H. Stephan, W. Richter, H. Zanker, W. Kraus, F. Emmerling, and G. Reck (2006). Transition Met. Chem. 31, 603.

39. D. Menon, R. T. Thomas, S. Narayanan, S. Maya, R. Jayakumar, F. Hussain, V. K. Lakshmanan, and S. V. Nair (2011). Carbohydr. Polym. 84, 887.

40. G. Geisberger, S. Paulus, E. B. Gyenge, C. Maake, and G. R. Patzke (2011). Small 7, 2808.

41. G. Geisberger, E. B. Gyenge, C. Maake, and G. R. Patzke (2013). Carbohydr. Polym. $91,58$.

42. G. Geisberger, S. Paulus, M. Carraro, M. Bonchio, and G. R. Patzke (2011). Chem. Eur. J. 17, 4619.

43. K. Pamin, B. Jachimska, K. Onik, J. Poltowicz, and R. Grabowski (2009). Catal. Lett. 127, 167.

44. M. Yamada and A. Maeda (2009). Polymer 50, 6076. 
45. H. M. L. Kang, Y. Yu, H. Pang, Y. Song, and D. Zhang (2013). Sensor. Actuat. B 177, 270.

46. J. H. Dawei Fan (2009). J. Phys. Chem. B 113, 7513.

47. Y. P. Shan, G. C. Yang, Y. T. Jia, J. Gong, Z. M. Su, and L. Y. Qu (2007). Electrochem. Commun. 9, 2224.

48. A. Anitha, V. V. D. Rani, R. Krishna, V. Sreeja, N. Selvamurugan, S. V. Nair, H. Tamura, and R. Jayakumar (2009). Carbohydr. Polym. 78, 672.

49. S. P. Chen, G. Z. Wu, D. W. Long, and Y. D. Liu (2006). Carbohydr. Polym. 64, 92.

50. Y. H. Feng, Z. G. Han, J. Peng, J. Lu, B. Xue, L. Li, H. Y. Ma, and E. B. Wang (2006). Mater. Lett. 60, 1588.

51. M. Aureliano and R. M. C. Gandara (2005). J. Inorg. Biochem. 99, 979.

52. I. V. Kozhevnikov (1998). Chem. Rev. 98, 171.

53. C. Tanielian (1998). Coord. Chem. Rev. 178, 1165.

54. R. Bodmeier, K. H. Oh, and Y. Pramar (1989). Drug Dev. Ind. Pharm. 15, 1475.

55. Y. Kawashima, T. Handa, A. Kasai, H. Takenaka, S. Y. Lin, and Y. Ando (1985). J. Pharm. Sci. 74, 264.

56. E. Chinea, D. Dakternieks, A. Duthie, C. A. Ghilardi, P. Gill, A. Mederos, S. Midollini, and A. Orlandini (2000). Inorg. Chim. Acta 298, 172.

57. G. A. Tsigdinos and C. J. Hallanda (1968). Inorg. Chem. 7, 437.

58. D. C. Duncan, T. L. Netzel, and C. L. Hill (1995). Inorg. Chem. 34, 4640.

59. J. H. Pa and T. L. Yu (2001). Macromol. Chem. Phys. 202, 985.

60. S. Tripathy, S. Das, S. P. Chakraborty, S. K. Sahu, P. Pramanik, and S. Roy (2012). Int. J. Pharm. 434, 292.

61. G. Liu, T. B. Liu, S. S. Mal, and U. Kortz (2006). J. Am. Chem. Soc. 128, 10103.

62. M. Aureliano and D. C. Crans (2009). J. Inorg. Biochem. 103, 536.

63. X. H. Wang, J. F. Liu, and M. T. Pope (2003). Dalton Trans. 2003, 957.

64. N. Liu, X. G. Chen, H. J. Park, C. G. Liu, C. S. Liu, X. H. Meng, and L. J. Yu (2006). Carbohydr. Polym. 64, 60.

65. K. Xing, X. G. Chen, M. Kong, C. S. Liu, D. S. Cha, and H. J. Park (2009). Carbohydr. Polym. 76, 17.

66. Y. Ma, P. T. Liu, C. L. Si, and Z. Liu (2010). J. Macromol. Sci., Phys 49, 994.

67. S. W. Ali, M. Joshi, and S. Rajendran (2011). Adv. Sci. Lett. 3, 452.

68. A. L. Neal (2008). Ecotoxicology 17, 362.

69. M. W. Calhoun and R. B. Gennis (1993). J. Bacteriol. 175, 3013.

70. M. Ammam and E. B. Easton (2013). J. Solid State Electrochem. 17, 137.

71. L. H. Bi, U. Kortz, M. H. Dickman, S. Nellutla, N. S. Dalal, B. Keita, L. Nadjo, M. Prinz, and M. Neumann (2006). J. Cluster Sci. 17, 143.

72. Y. L. Li, X. R. Yang, F. Yang, Y. P. Wang, P. H. Zheng, and X. X. Liu (2012). Electrochim. Acta 66, 188.

73. P. Sami and K. Rajasekaran (2009). J. Chem. Sci. 121, 155.

74. M. Vairalakshmi, V. Raj, P. Sami, and K. Rajasekaran (2011). Transition Met. Chem. 36, 875.

75. T. Yokota, S. Fujibayashi, Y. Nishiyama, S. Sakaguchi, and Y. Ishii (1996). J. Mol. Catal. A 114, 113.

76. I. V. Kozhevnikov (1997). J. Mol. Catal. A 117, 151.

77. R. Neumann (2010). Inorg. Chem. 49, 3594.

78. C. L. Hill and C. M. Prosser-McCartha Photosensitization and photocatalysis using inorganic and organometallic compounds (Kluver Academic Publishers, Dordrecht, 1997).

79. W. L. Du, S. S. Niu, Y. L. Xu, Z. R. Xu, and C. L. Fan (2009). Carbohydr. Polym. 75, 385.

80. C. N. Lok, C. M. Ho, R. Chen, Q. Y. He, W. Y. Yu, H. Sun, P. K. H. Tam, J. F. Chiu, and C. M. Che (2007). J. Biol. Inorg. Chem. 12, 527.

81. N. Bhattarai, D. Edmondson, O. Veiseh, F. A. Matsen, and M. Q. Zhang (2005). Biomaterials 26, 6176.

82. M. Y. Kim and J. Lee (2011). Carbohydr. Polym. 84, 1329.

83. Q. C. Zhao, X. D. Feng, S. L. Mei, and Z. X. Jin (2009). Nanotechnology 20, 105101.

84. H. L. Tan, S. R. Guo, S. B. Yang, X. F. Xu, and T. T. Tang (2012). Acta Biomaterialia 8, 2166.

85. L. Ma, C. Y. Gao, Z. W. Mao, J. Zhou, J. C. Shen, X. Q. Hu, and C. M. Han (2003). Biomaterials 24, 4833.

86. K. Saita, S. Nagaoka, T. Shirosaki, M. Horikawa, S. Matsuda, and H. Ihara (2012). Carbohydr. Res. 349, 52 . 
87. Z. M. Cui, W. Xing, C. P. Liu, J. H. Liao, and H. Zhang (2009). J. Power Sources 188, 24.

88. S. P. Liu, L. Xu, F. Y. Li, W. H. Guo, Y. Xing, and Z. X. Sun (2011). Electrochim. Acta 56, 8156.

89. I. Leceta, P. Guerrero, and K. de la Caba (2013). Carbohydr. Polym. 93, 339. 